\title{
Stability of a Novel Intraocular Lens Design: Comparison of Two Trifocal Lenses
}

\author{
Francisco Poyales, MD; Nuria Garzón, OD, PhD; Jos J. Rozema, PhD; Concepción Romero, MD; \\ Begoña Ortíz de Zárate, MD
}

\begin{abstract}
PURPOSE: To compare visual outcomes, rotational stability, and centration in a randomized controlled trial in patients undergoing cataract surgery who were bilaterally implanted with two different trifocal intraocular lenses (IOLs) with a similar optical zone but different haptic shape.
\end{abstract}

METHODS: Twenty-one patients (42 eyes) with cataract and less than $1.50 \mathrm{D}$ of corneal astigmatism underwent implantation of one FineVision/MicoF IOL in one eye and one POD FineVision IOL in the contralateral eye (PhysIOL, Liège, Belgium) at IOA Madrid Innova Ocular, Madrid, Spain. IOL allocation was random. Outcome measures, all evaluated 3 months postoperatively, included monocular and binocular uncorrected distance (UDVA), corrected distance (CDVA), distance-corrected intermediate (DCIVA), and near (DCNVA) visual acuity (at 80,40 , and $25 \mathrm{~cm}$ ) under photopic conditions, refraction, IOL centration, haptic rotation, dysphotopsia, objective quality of vision and aberration quantification, patient satisfaction, and spectacle independence.

RESULTS: Three months postoperatively, mean monocular UDVA, CDVA, DCIVA, and DCNVA $(40 \mathrm{~cm})$ under photopic conditions were $0.04 \pm 0.07,0.01 \pm 0.04$, $0.15 \pm 0.11$, and $0.16 \pm 0.08$ logMAR for the eyes implanted with the POD FineVision IOL and $0.03 \pm 0.05$, $0.01 \pm 0.02,0.17 \pm 0.12$, and $0.14 \pm 0.08$ logMAR for those receiving the FineVision/MicroF IOL. Moreover, the POD FineVision IOL showed similar centration $(P$ $>$.05) and better rotational stability $(P<.05)$ than the FineVision/MicroF IOL. Regarding halos, there was a minimal but statistically significant difference, obtaining better results with FineVision/MicroF. Full spectacle independence was reported by all patients.

CONCLUSIONS: This study revealed similar visual outcomes for both trifocal IOLs under test (POD FineVision and FineVision/MicroF). However, the POD FineVision IOL showed better rotational stability, as afforded by its design.

[J Refract Surg. 201X;XX(X):XX-XX.]

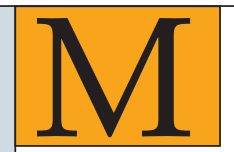

ultifocal intraocular lenses (IOLs) enable spectacle independence ${ }^{1}$ by providing several points of focus. A new generation of multifocal IOLs, known as trifocal IOLs (designed with three focal points) entered the European market in 2010, with the launch of the FineVision/MicroF IOL (PhysIOL, Liège, Belgium). Many studies describing optical bench testing and clinical outcomes for this IOL have been published since then.

The presence of astigmatism in multifocal IOLs scatters each point of focus, resulting in multifocality failure. Therefore, astigmatism correction should also be a surgical goal. An accurate alignment of the toric IOL with the astigmatism axis is key for maximum vision correction. This can only be achieved if the IOL remains stable within the eye (ie, it must not rotate after implantation). The original FineVision/ MicroF IOL, a trifocal IOL model designed for microincision cataract surgery, was adapted with a new double C-loop haptic design that should guarantee the IOL's rotational stability. This new IOL model, which includes a toric component, was named POD FineVision.

In this study, we assessed the effect on rotational and capsular centration stability of this new haptic design and whether or not this leads to an improved visual performance to validate the material and the design of the POD FineVision IOL for toric versions.

\section{PATIENTS AND METHODS}

\section{StUdY DESIGN}

In this randomized controlled trial, we compared the efficacy and rotational stability of two IOLs: a hydrophilic acryl-

From IOA Madrid Innova Ocular, Madrid, Spain (FP, NG, CR, BOdZ); and the Department of Ophthalmology, Antwerp University Hospital, Edegem, Belgium (JJR).

Submitted: June 13, 2015; Accepted: February 4, 2016

The authors have no financial or proprietary interest in the materials presented herein.

Correspondence: Francisco Poyales, MD, IOA Madrid Innova Ocular, Calle Galileo, 104, 28003 Madrid, Spain.E-mail: ioamadrid@hotmail.es

doi:10.3928/1081597X-20160428-04 
ic $(26 \%)$ trifocal IOL (POD FineVision) and another hydrophilic acrylic (25\%) trifocal IOL (FineVision/ MicroF). Both of them have exactly the same design for the optical zone.

The study adhered to the tenets of the Declaration of Helsinki and was approved by the local ethical committee. The risk of binocular imbalance resulting from the implantation of two different IOL models was carefully considered. It was estimated to be minimal because the two IOL models provide the same MTF and transmittance curves when tested on an optical bench. All patients received sufficient information about the study before providing written informed consent.

The epiR package 0.9 to 30AQ1 was used to determine the cohort size with an average $0.03 \operatorname{logMAR}$, a discrimination of one $\log$ MAR line in visual acuity, with a standard deviation of 0.08 . Based on these assumptions, with an alpha level of 0.05 and power of 0.9 , it was calculated that 9 patients were required in each group.

Selection criteria were the need for bilateral cataract surgery, no ocular comorbidities, and realistic expectations by the patient. Twenty-one patients received both IOLs. Following random allocation, the POD FineVision IOL was implanted in one eye and the FineVision/MicroF IOL in the fellow eye. The selected patients had binocular age-related cataract with preoperative corneal astigmatism less than $1.50 \mathrm{D}$, a preoperative $\operatorname{logMAR}$ visual acuity greater than 1.0, and normal findings in their medical record and physical examination unless the investigator considered a particular abnormality to be clinically irrelevant.

Any of the following precluded an individual from participating in the study: ophthalmic diseases such as pseudoexfoliation syndrome, floppy iris syndrome, corneal pathologies, retinal pathology (diabetic maculopathy, myopic maculopathy, or age-related macular degeneration) and history of ocular surgery or trauma.

\section{IOL DESCRIPTION}

Both IOLs evaluated in this study are aspheric trifocal diffractive IOLs manufactured by PhysIOL (Liège, Belgium). They have exactly the same diffractive pattern and a similar refractive index (1.46 and 1.47), which means equivalent curvatures. The POD FineVision (Figure A, available in the online version of this article) is a double C-loop IOL with $5^{\circ}$ angulation made of $26 \%$ hydrophilic material with ultraviolet filtration and a blue-light blocker. The optic body diameter is 6 $\mathrm{mm}$ and the overall diameter is $11.4 \mathrm{~mm}$. It is available in powers ranging from +6.00 to $+35.00 \mathrm{D}$. The FineVision/MicroF (Figure B, available in the online version of this article) is a four-loop IOL with $5^{\circ}$ angulation made of $25 \%$ hydrophilic material with ultraviolet filtration and a blue-light blocker. The optic body diameter is $6.15 \mathrm{~mm}$ and the overall diameter is $10.75 \mathrm{~mm}$. It is available in powers ranging from +10.00 to $+35.00 \mathrm{D}$.

\section{MARKING MethOd}

The marking method used in this study was described previously by Garzón et al. ${ }^{2}$ During the preoperative preparation of the patient, two marks were made at the limbus, on the horizontal axis $\left(0^{\circ}\right.$ to $\left.180^{\circ}\right)$, using a fine-tipped gentian violet marker (Devon Skin Marker, Fine Tip 151): one at the 9-o'clock position and the other at the 3-o'clock position under slit-lamp observation. A photograph was then taken of the patient standing at least $2.5 \mathrm{~m}$ away from the camera, with the head in its normal position (no chinrest or other support was used). Both eyes were kept open at all times, thus avoiding the cyclotorsion that can occur during blinking. Furthermore, images were always taken at a distance to prevent cyclotorsion, which might occur when looking at a close object. The position of the surgeon-made marks was measured on the acquired image. Thus, once a patient was supine, the exact position of the marks was well established, irrespective of any cyclotorsion that might occur during surgery. The camera used to take the above-mentioned preoperative images was a Nikon Coolpix P90 cameraAQ1, with a 26- to 624-mm lens (35mm equivalent), a charge coupled device of 12.10 effective megapixels, and a $24 \times$ (optical) $/ 4 \times$ (digital) zoom. The camera was placed on a tripod and connected to a bubble level to ensure the photograph was perfectly straight. The optical zooming option allowed us to simultaneously photograph both eyes. The photograph was then exported to a computer equipped with the Scale 2.0 package (Software R. Sgrillo, BrazilAQ2) to enable precise angle measurements. On the photograph, we measured the angle the corneal marks formed with the horizontal line that transects the corneal reflex (Figure 1). This provided the exact position of the marks and their angular position relative to the 'real' $0^{\circ}$ to $180^{\circ}$ line. Next, once the patient was lying down, the surgeon marked the axis that was to be aligned with the IOL's index marks. For this purpose we used Méndez's ring and took the initial marks as reference, with correction for their angular position relative to the real $0^{\circ}$ to $180^{\circ}$ line. Finally, the preoperative image and the last photograph obtained during surgery showing the final IOL's axis position were compared to calculate the misalignment due to the marking method.

\section{Surgical Procedure}

The same surgeon (FP) performed all surgeries. All surgery was done under topical anesthesia. For phaco- 


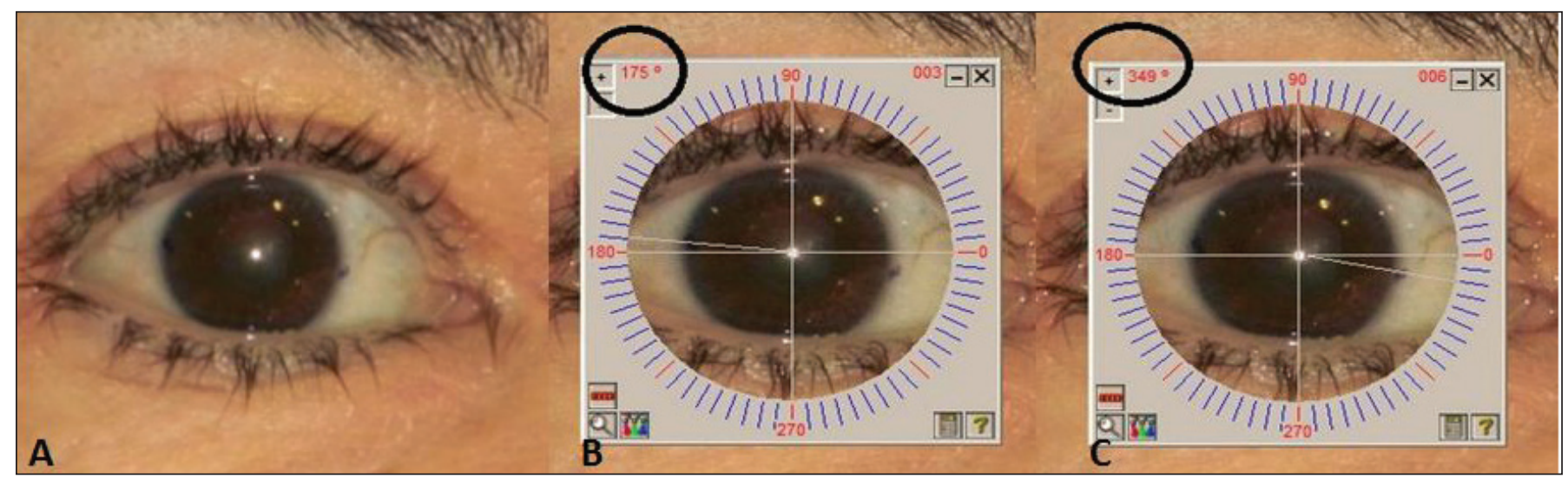

Figure 1. (A) Two marks placed at the limbus on the horizontal axis $\left(0^{\circ}\right.$ to $\left.180^{\circ}\right)$ at the 9 - and 3-0'clock positions performed under slit-lamp observation. (B-C) The exact position of the marks and their angular difference with respect to the "real" $0^{\circ}$ to $180^{\circ}$ line.

emulsification, the surgeon made a 2.2-mm clear-cornea incision. Next, a continuous curvilinear capsulorhexis measuring approximately $5.5 \mathrm{~mm}$ in diameter was created. Two ophthalmic viscosurgical devices were used during the surgery: the cohesive Healon (Abbott Laboratories Inc., Abbot Park, IL) and the dispersive Amvisc (Bausch \& Lomb, Inc., Rochester, NY). The IOL was then implanted in the capsular bag with a single-use injection system (Microset; PhysIOL). Following IOL implantation, all traces of ophthalmic viscosurgical devices were removed.

\section{EXAMINATION}

Preoperative evaluations included anterior chamber depth, axial length, corneal power, white-to-white distance, corrected distance visual acuity, intraocular pressure, and photopic and mesopic pupil diameters.

Patients were seen at 1 day, 1 week, 1 month, and 3 months following surgery. At each visit, visual acuity was measured and patients underwent a slit-lamp examination. At the 1-week and 1-month postoperative visits, refraction was also assessed.

Additional variables that were measured in the 3-month postoperative visit included: Objective Scattering Index (OSI), MTF, and Strehl ratio, which were measured with the OQAS (Visiometrics SL, Terrassa, Spain); centration (mm), determined from slit-lamp photographs; rotation $\left(^{\circ}\right)$, determined from slit-lamp photographs; ocular aberrations (spherical aberration and tilt), using the OPD Scan III-refractive power/corneal analyzer system (Nidek Co., Ltd.AQ1); halos, using the Halo v1.0 software (Laboratory of Vision Sciences and Applications, University of Granada, Granada, Spain); refraction, visual acuity (logMAR) at any distance (4 $\mathrm{m}$ and 80, 40, and $25 \mathrm{~cm}$ ) with Early Treatment Diabetic Retinopathy Study and Spanish RADNER Vissum chart; subjective satisfaction level, assessed by means of an ad hoc questionnaire written for this particular purpose; and pupil size in photopic and mesopic conditions, measured with the OPD Scan III.

\section{StABILITY ASSESSMENT}

Centration and rotation were evaluated using validated methods. ${ }^{3,4}$ IOL rotation was assessed by retrospective analysis of slit-lamp photographs via a triangulation method (IOL mark, IOL center, and anatomic mark), using the sharpest optic-haptic junction as a mark of the IOL positioning with respect to time.

The position of the IOL's geometric center relative to the geometric center of the dilated pupil was determined by the same observer using a program written in MathLab 6.5 (The MathWorks, Inc., Natick, MA) to process digital photographs of the pupil. A first ellipse was drawn following the contours of the IOL optical zone, and a second one was drawn following the border of the limbus. The computer then calculated the shift between these two ellipses' geometric centers.

As part of the regular postoperative follow-up, digital retroilluminated slit-lamp photographs of each eye were taken the day of the surgery, and at 1 day, 1 week, 1 month, and 3 months postoperatively. Before slitlamp photographs were taken, eyes were dilated to a pupil diameter of at least $6.5 \mathrm{~mm}$ by means of a drop of tropicamide $0.5 \%$ solution (MonofreeAQ1).

Photographs were analyzed using custom-made processing routines written in MathLab (The MathWorks, Inc.). This software program uses an easily recognizable landmark on the sclera (eg, a blood vessel), a landmark on the IOL (eg, the haptic), and the IOL's optic center to define a triangle (Figure 2). These landmarks were defined by means of mouse clicks on the photographs, and the IOL's optic center was determined by fitting an ellipse onto the IOL optic edge. Next, the IOL's orientation angle $\theta$ was defined by tracing the 


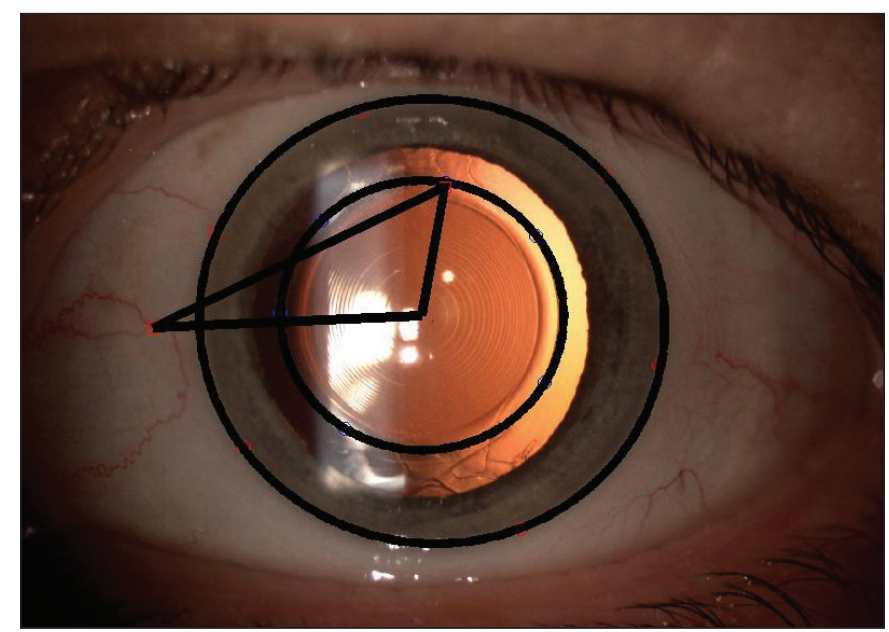

Figure 2. The photograph of the lens in situ shows the triangle between the limbus center, the anatomic mark (blood vessel crossing in this case), and the haptic-optic junction.

lines connecting the scleral landmark and the IOL landmark with the IOL optic center. Because the shape and center of the limbus do not change significantly over a 6-month period, it is possible to determine changes in IOL orientation over time by comparing the corresponding triangles from photographs taken at different follow-up visits.

The photographic evaluation method used for image acquisition required that at least three-quarters of the IOL optic edge outline and recognizable landmarks on the IOL and the sclera were visible in the photograph for accurate determination of the change in IOL orientation. Photographs that did not meet these criteria were not evaluated.

For the purpose of this study, a positive rotation angle $\theta$ was defined as the angle resulting from a clockwise rotation and a negative rotation angle $\theta$ was defined as the angle resulting from a counterclockwise rotation.

\section{Statistical Analysis}

For all quantitative variables, summary tables containing mean, standard deviation, and maximum and minimum values were created. The $\mathrm{R}$ code was used to determine differences between groups and between preoperative and postoperative assessments. Due to the sample size, the robust non-parametric Wilcoxon rank sum test was employed. In all tests, a $P$ value of .05 was considered significant. An odds ratio analysis was performed to compare the number of rotations greater than $5^{\circ}$ between the two groups.

\section{RESULTS}

\section{Baseline Characteristics}

The FineVision/Micro F and the POD FineVision groups were comparable across all preoperative pa- rameters (Table A, available in the online version of this article). This was expected because the groups were matched: for each patient one eye received the FineVision/MicroF lens and the fellow eye received the POD FineVision lens.

The preoperative visual acuity was $0.16 \pm 0.16$ logMAR (range: 0.8 to 0.05 logMAR) for the FineVision/ MicroF group and $0.17 \pm 0.18 \operatorname{logMAR}$ (range: 0.7 to $0.05 \operatorname{logMAR}$ ) for the POD FineVision group. The mean age at the time of surgery was $64 \pm 9.0$ years.AQ3

\section{Surgical and Clinical Outcomes}

All surgeries were uneventful. One eye implanted with the POD FineVision IOL had a Seidel leakage that required a suture. Posterior capsule opacification could be seen 3 months postoperatively in one eye that had been implanted with the POD FineVision IOL. One patient implanted with the POD FineVision IOL in his first eye experienced pronounced negative dysphotopsia. However, it resolved after 3 months and the patient accepted surgery in the fellow eye. No postoperative dysphotopsia was reported for this fellow eye.

\section{VISUAL ACUITY}

As can be seen in Table 1, all postoperative visual acuity values were better than $0.3 \log$ MAR. No significant difference could be observed between the two groups at any follow-up visit.

\section{REFRACTION}

At 3 months postoperatively, the spherical equivalent was $0.03 \pm 0.31 \mathrm{D}$ (range: -0.5 to $0.5 \mathrm{D}$ ), the cylinder was $-0.03 \pm 0.11 \mathrm{D}$ (range: -0.5 to $0 \mathrm{D}$ ), and the sphere was $0.04 \pm 0.29 \mathrm{D}$ (range: -0.5 to $0.5 \mathrm{D}$ ) for the POD FineVision group. For the FineVision/MicroF group, the spherical equivalent was $0.00 \pm 0.23 \mathrm{D}$ (range: -0.5 to $0.5 \mathrm{D}$ ), the cylinder was $-0.06 \pm 0.16 \mathrm{D}$ (range: -0.5 to $0 \mathrm{D})$, and the sphere was $0.03 \pm 0.19 \mathrm{D}(-0.25$ to 0.5 D). The refractive outcomes at each follow-up visit are shown in Figure $\mathbf{C}$ (available in the online version of this article).

\section{Centration}

Table 2 summarizes IOL centration status with respect to pupil edge for each IOL group and at each follow-up visit. These data show that both IOLs provided good centration. Even though the POD FineVision IOL seems to provide slightly better centration than the FineVision/MicroF IOL, only the 1-month postoperative differences were statistically significant.

Rotational stability was assessed using slit-lamp photographs at 1 day and 3 months following surgery. The 


\begin{tabular}{|c|c|c|c|c|c|}
\hline \multicolumn{6}{|c|}{$\begin{array}{c}\text { TABLE } 1 \\
\text { Visual Acuity }\end{array}$} \\
\hline IOL & UDVA & CDVA & DCIVA $80 \mathrm{~cm}$ & DCNVA $40 \mathrm{~cm}$ & DCNVA $25 \mathrm{~cm}$ \\
\hline \multicolumn{6}{|l|}{ Preoperative } \\
\hline FineVision/MicroF & - & $\begin{array}{c}0.16 \pm 0.16 \\
(0.8 \text { to } 0.05)\end{array}$ & - & - & - \\
\hline POD FineVision & - & $\begin{array}{c}0.17 \pm 0.18 \\
(0.7 \text { to } 0.05)\end{array}$ & - & - & - \\
\hline \multicolumn{6}{|l|}{1 week postoperative } \\
\hline POD FineVision & $\begin{array}{c}0.05 \pm 0.06 \\
(0.2 \text { to } 0)\end{array}$ & $\begin{array}{r}0.01 \pm 0.02 \\
(0.05 \text { to } 0)\end{array}$ & $\begin{array}{r}0.12 \pm 0.07 \\
(0.3 \text { to } 0.0)\end{array}$ & $\begin{array}{r}0.17 \pm 0.10 \\
(0.4 \text { to } 0.0)\end{array}$ & $\begin{array}{r}0.30 \pm 0.11 \\
(0.5 \text { to } 0.1)\end{array}$ \\
\hline FineVision/MicroF & $\begin{array}{r}0.04 \pm 0.07 \\
(0.25 \text { to } 0)\end{array}$ & $\begin{array}{r}0.01 \pm 0.02 \\
(0.05 \text { to } 0)\end{array}$ & $\begin{array}{r}0.11 \pm 0.08 \\
(0.2 \text { to }-0.1)\end{array}$ & $\begin{array}{r}0.15 \pm 0.10 \\
(0.4 \text { to } 0.0)\end{array}$ & $\begin{array}{r}0.27 \pm 0.09 \\
(0.4 \text { to } 0.1)\end{array}$ \\
\hline \multicolumn{6}{|l|}{1 month postoperative } \\
\hline POD FineVision & $\begin{array}{r}0.03 \pm 0.05 \\
(0.15 \text { to } 0)\end{array}$ & $\begin{array}{r}0.00 \pm 0.00 \\
(0.0 \text { to } 0.0)\end{array}$ & $\begin{array}{r}0.13 \pm 0.09 \\
(0.3 \text { to } 0.1)\end{array}$ & $\begin{array}{r}0.12 \pm 0.08 \\
(0.3 \text { to } 0.0)\end{array}$ & $\begin{array}{r}0.30 \pm 0.10 \\
(0.5 \text { to } 0.1)\end{array}$ \\
\hline FineVision/MicroF & $\begin{array}{r}0.02 \pm 0.04 \\
(0.15 \text { to } 0)\end{array}$ & $\begin{array}{c}0.00 \pm 0.002 \\
(0.05 \text { to } 0)\end{array}$ & $\begin{array}{r}0.13 \pm 0.10 \\
(0.3 \text { to }-0.1)\end{array}$ & $\begin{array}{r}0.13 \pm 0.11 \\
(0.4 \text { to } 0.0)\end{array}$ & $\begin{array}{r}0.30 \pm 0.07 \\
(0.4 \text { to } 0.1)\end{array}$ \\
\hline \multicolumn{6}{|c|}{3 months postoperative } \\
\hline POD FineVision & $\begin{array}{c}0.04 \pm 0.07 \\
(0.2 \text { to } 0)\end{array}$ & $\begin{array}{r}0.01 \pm 0.04 \\
(0.15 \text { to } 0)\end{array}$ & $\begin{array}{r}0.15 \pm 0.11 \\
(0.3 \text { to }-0.1)\end{array}$ & $\begin{array}{c}0.16 \pm 0.08 \\
(0.3 \text { to } 0)\end{array}$ & $\begin{array}{r}0.35 \pm 0.11 \\
(0.6 \text { to } 0.2)\end{array}$ \\
\hline FineVision/MicroF & $\begin{array}{c}0.03 \pm 0.05 \\
(0.2 \text { to } 0)\end{array}$ & $\begin{array}{r}0.01 \pm 0.02 \\
(0.07 \text { to } 0)\end{array}$ & $\begin{array}{c}0.17 \pm 0.12 \\
(0.4 \text { to }-0.1)\end{array}$ & $\begin{array}{r}0.14 \pm 0.08 \\
(0.3 \text { to } 0.0)\end{array}$ & $\begin{array}{r}0.34 \pm 0.08 \\
(0.5 \text { to } 0.2)\end{array}$ \\
\hline \multicolumn{6}{|c|}{$\begin{array}{l}\text { IOL = intraocular lens; UCVA = uncorrected distance visual acuity; CDVA = corrected distance visual acuity; DCIVA = distance-corrected intermediate visual acuit } \\
D C N V A=\text { distance-corrected near visual acuity } \\
\text { aValues are given as logMAR mean } \pm \text { standard deviation (minimum to maximum). } \\
\text { The lenses are manufactured by Phys/OL, Liège, Belgium. }\end{array}$} \\
\hline
\end{tabular}

TABLE 2

Mean Distance of the IOL Center to the Pupil Center (mm)

\begin{tabular}{lccc}
\hline Time & POD FineVision & FineVision/MicroF & $P$ \\
\hline Day of surgery $(\mathrm{mm})$ & $0.22 \pm 0.12$ & $0.27 \pm 0.13$ & .69 \\
1 day postoeprative $(\mathrm{mm})$ & $0.24 \pm 0.11$ & $0.29 \pm 0.20$ & .33 \\
1 week postoperative $(\mathrm{mm})$ & $0.20 \pm 0.11$ & $0.25 \pm 0.13$ & .50 \\
1 month postoperative $(\mathrm{mm})$ & $0.19 \pm 0.10$ & $0.30 \pm 0.17$ & $.032^{\mathrm{a}}$ \\
3 months postoperative $(\mathrm{mm})$ & $0.17 \pm 0.06$ & $0.24 \pm 0.19$ & .25 \\
\hline
\end{tabular}

$\mathrm{IOL}=$ intraocular lens

asignificant.

The lenses are manufactured by Phys/OL, Liège, Belgium.

mean IOL rotation was $1.85^{\circ} \pm 1.01^{\circ}$ for the POD FineVision group (range: $0.32^{\circ}$ to $3.13^{\circ}$ ) and $3.30^{\circ} \pm 3.88^{\circ}$ (range: $0.26^{\circ}$ to $11.26^{\circ}$ ) for the FineVision/MicroF group.

There were no statistically significant differences $(P$ $=.42$ ) between the two groups due to the high standard deviation within the FineVision/MicroF group. In the odds ratio analysis, we had two IOLs that rotated more than $10^{\circ}$ in the FineVision/MicroF group, whereas none of the IOLs in the POD FineVision group rotated more than $5^{\circ}$. This difference between groups was not statistically significant $(\mathrm{z}=1.00, P=.31)$.

\section{HALOMETRY}

The discrimination of peripheral stimuli in the presence of halos around a central stimulus was evaluated using the disturbance index. This index has a value between 0 and 1 and the greater the index, the lower the discrimination capacity. The discrimination index is equal to 1 minus the disturbance index. The outcomes of the halo quantification method are listed in Table 3. There was little visual disturbance with either IOL and no statistically significant differences emerged between the two groups. There was no cor- 


\begin{tabular}{|c|c|c|c|}
\hline \multicolumn{4}{|c|}{$\begin{array}{l}\text { Halo Quantification Using the Discrimination Index and } \\
\text { the Related Disturbance Index in Groups Implanted With the Two Lenses }\end{array}$} \\
\hline Parameter & FineVision/MicroF & POD FineVision & $P$ \\
\hline Discrimination index (linear) & $0.92 \pm 0.07$ & $0.89 \pm 0.09$ & .073 \\
\hline Discrimination index (quadratic) & $0.95 \pm 0.06$ & $0.92 \pm 0.08$ & .061 \\
\hline Disturbance index (linear) & $0.08 \pm 0.07$ & $0.11 \pm 0.09$ & .069 \\
\hline Disturbance index (quadratic) & $0.05 \pm 0.06$ & $0.08 \pm 0.08$ & .061 \\
\hline
\end{tabular}

\begin{tabular}{|lcc|}
\hline \multicolumn{2}{|c|}{ Aberrations and Image Quality } & TABLE 4 \\
\hline Parameter & FineVision/MicroF & POD FineVision \\
\hline SA & $0.24 \pm 0.12$ & $0.26 \pm 0.19$ \\
HOA RMS internal & $0.33 \pm 0.16$ & $0.33 \pm 0.13$ \\
TiltX $(\mu \mathrm{m})$ & $0.11 \pm 0.20$ & $-0.08 \pm 0.39$ \\
TiltY $(\mu \mathrm{m})$ & $-0.04 \pm 0.33$ & $0.02 \pm 0.42$ \\
OSI & $2.18 \pm 0.91(1.1$ to 4.7$)$ & $2.48 \pm 1.08(1.1$ to 4.8$)$ \\
MTF & $29.21 \pm 9.22$ & $29.88 \pm 12.95$ \\
Strehl ratio & $0.18 \pm 0.05$ & $0.18 \pm 0.06$ \\
\hline SA $=$ spherical aberration; HOA RMS $=$ higher order aberrations root mean square; OSI = Objective Scattering Index; MTF = modulation transfer function \\
The lenses are manufactured by Phys/OL, Liège, Belgium.
\end{tabular}

relation between pupil diameter and the disturbance index $\left(\mathrm{r}^{2}<0.001\right)$.

\section{AberRations and Optical Quality}

The OPD Scan and OQAS were used to measure optical aberrations and image quality, respectively, following IOL implantation. The outcomes are shown in Table 4. There were no statistically significant differences between the two groups' outcomes except for TiltX $(P=.008)$.

Although the MTF and Strehl ratio were close to that of a normal population, the OSI was higher. Nevertheless, it remained, on average, within the range of the normal population $(0.40$ to -3.00$){ }^{5}$

\section{QUestionnaire}

Subjective outcomes are illustrated in Figure 3 and are consistent with the halometry data. More halos were perceived with the POD FineVision IOL, although they were uncommon, and the disturbance was minimal.

Patients ranked their vision from 0 (blindness) to 10 (perfect vision). The mean score was $8.29 \pm 1.49$ for far vision, $8.00 \pm 1.71$ for near vision, $8.31 \pm 1.80$ for intermediate vision, and $7.29 \pm 1.82$ for night vision. Ninety percent of the patients stated that they would undergo surgery again if they had to. Two patients were not happy with their outcomes. One stated that he would not undergo surgery again despite rating his vision at 8 of 10 . The other patient was disturbed by the appearance of halos. Four additional patients also reported bothersome halos. Although scoring lower than day vision $(P=.01)$, night vision was only $11 \%$ worse than day vision.

When patients were asked to compare the comfort provided by the two IOLs when looking at different distances, $66.77 \%$ of them reported perceiving no differences between the two IOLs, $14.29 \%$ of patients gave a better rating to the FineVision/Micro F model, and $19.05 \%$ of them preferred the POD FineVision model. Another factor that was relevant for the patients was the occurrence rate of dysphotopic phenomena, which may be related to the different optical zone sizes that these two lenses have. In this context, $95.24 \%$ of the patients found no differences between the two eyes, whereas $4.76 \%$ of them perceived more halos with the POD FineVision model, which has a smaller 6-mm optical zone (Figure 6).

\section{DISCUSSION}

The two lenses evaluated in our study showed similar visual acuity scores, with no statistically significant differences between the lenses at any of the three distances evaluated or at any of the follow-up visits. This suggests that the difference in lens material is less rel- 


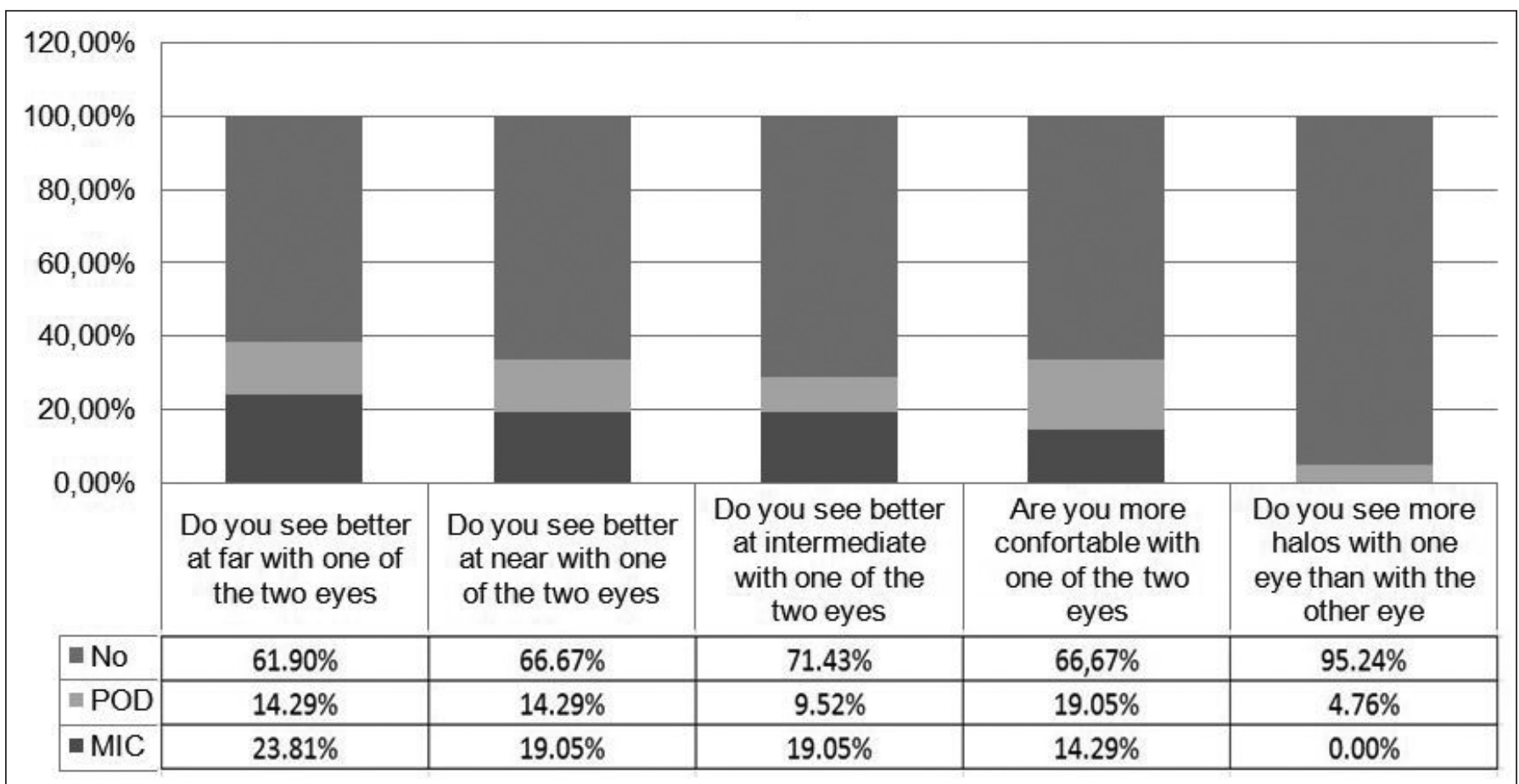

Figure 3. Stack histogram showing answers to the questionnaire. Blue $=$ FineVision/MicroF, red $=$ POD FineVision, green $=$ no difference. The lenses are manufactured by PhysIOL, Liège, Belgium.AQ4

evant than the diffractive design. Indeed, Marques and Ferreira $^{6}$ showed statistical differences between AT Lisa Tri and FineVision/MicroF IOL performance for distance-corrected intermediate and near vision acuity.

The amount of addition plays a critical role in reading distance. Several studies have shown that bifocal IOLs with a higher addition power provide worse visual acuity in the intermediate range than lenses with lower addition power. ${ }^{7-10}$ Consequently, newly launched bifocal IOLs tend to have a design similar to previous models but with lower addition powers to improve visual outcomes in the intermediate range. Nevertheless, we must also be aware that a too low addition is detrimental for near vision. ${ }^{4}$ The results obtained with trifocal IOLs show that including a third focal point (to improve intermediate vision) does not result in a loss of near visual acuity, as is the case with bifocal IOLs. Similarly, the inclusion of a third focal point does not compromise distance vision. ${ }^{12-17}$ Furthermore, none of the patients included in our study reported postoperative spectacle dependence in performing any of the activities of daily living. Both POD FineVision and FineVision/MicroF IOLs yielded a better visual acuity at $40 \mathrm{~cm}$ than at $25 \mathrm{~cm}$, which is consistent with the visual requirements of modern life, such as the use of electronic devices including smartphones or tablets.

Regarding differences in material and haptic design, Bozukova et al. ${ }^{18}$ reported findings from a study in which 11 IOLs from different platforms were compared in vitro. The 4-loop haptic design lens (FineVision/MicroF) showed greater compression in the capsular bag than the double C-loop haptic lens (POD FineVision), but that did not compromise IOL stability with regard to IOL position. Furthermore, they concluded that the double C-Loop or the 4-loop closed haptics employed by the two platforms evaluated in this study provide a moderate compression force contributing to the lenses' anteroposterior stability. By contrast, in that same study, Bozukova et al. ${ }^{18}$ showed that plate haptic lenses (eg, the AT Lisa Tri lens) have lower formability and thereby provide higher radial compressive forces in the capsular bag. Similar to these ex vivo studies, our results show that the two lenses are stable, although the POD FineVision design was more centered and had higher rotational stability. Our outcomes with the double C-loop platform are consistent with the data published by Chassain. ${ }^{19,20}$

In terms of visual quality and Strehl ratio, the results obtained with FineVision/MicroF and POD FineVision models used in the current study are more robust than those presented by Mojzis et al. ${ }^{21}$ for the AT LisaTri lens. The MTF and OSI results were also excellent, but no clinical studies with other models of trifocal lenses have been published to date and, therefore, we are unable to discuss these particular findings within the context of other works.

In the current study, internal higher order aber- 
rations were similar for the two implanted models. Rohart et al. ${ }^{22}$ and Taketani et al. ${ }^{23}$ estimated that hydrophobic lenses caused greater aberrations than hydrophilic lenses. Photic phenomena such as halos or glare in multifocal lenses have been previously reported.1,11,24 Moreover, it has been claimed that such phenomena are more prevalent with hydrophobic IOLs. ${ }^{25,26}$ In our study, patients were specifically questioned about photic phenomena and halometry was employed. For both investigations, although the differences were slight, the objective and subjective data showed better values in the FineVision/MicroF lens group. Because the only difference between the two IOLs is the optical diameter $(6.15 \mathrm{~mm}$ for the FineVision/MicroF and $6 \mathrm{~mm}$ for the POD FineVision) and no other visual outcomes were different, we believe that this must be the factor that explains the minimal difference in halo occurrence rate. Only one patient reported edge dysphotopsia in one eye.

This study has limitations, mainly due to the small number of participating patients. Therefore, more extensive studies in terms of both number of patients and length of the follow-up period are needed to gain greater insight into these lenses' behavior. A long-term study would be particularly useful to provide information on the IOL material stability because hydrophilic IOLs may have calcification. The occurrence of calcification is nevertheless low: in a study of 806 cases of IOLs with the same $26 \%$ hydrophilic acrylic raw material as the POD FineVision IOL, Tassignon et al. ${ }^{27}$ reported only two cases of calcification.

The double C-loop haptic design of the POD FineVision IOL provided good rotational stability while achieving similar visual performance to the FineVision/MicroF model. This study demonstrated the equivalence of the non-toric version of these two IOLs in terms of visual performance, to validate the material and the design of the POD FineVision IOL for toric versions. The toric POD FineVision IOL is available on the market and it will be interesting to directly measure the outcomes it achieves in term of quality of vision, refractive predictability, and positional stability.

\section{AUTHOR CONTRIBUTIONS}

Study concept and design (FP, NG, JJR); data collection (NG); analysis and interpretation of data (FP, NG, CR, BOdZ); writing the manuscript (NG); critical revision of the manuscript (FP, JJR, CR, BOdZ); statistical expertise (FP, NG); supervision (FP)

\section{REFERENCES}

1. de Vries NE, Nuijts RM. Multifocal intraocular lenses in cataract surgery: literature review of benefits and side effects. J Cataract Refract Surg. 2013;39:268-278.
2. Garzón N, Poyales F, de Zárate BO, Ruiz-García JL, Quiroga JA. Evaluation of rotation and visual outcomes after implantation of monofocal and multifocal toric intraocular lenses. J Refract Surg. 2015;31:90-97.

3. Verbruggen KH, Rozema JJ, Gobin L, Coeckelbergh T, De Groot $\mathrm{V}$, Tassignon MJ. Intraocular lens centration and visual outcomes after bag-in-the-lens implantation. J Cataract Refract Surg. 2007;33:1267-1272.

4. Rozema JJ, Gobin L, Verbruggen K, Tassignon MJ. Changes in rotation after implantation of a bag-in-the-lens intraocular lens. J Cataract Refract Surg. 2009;35:1385-1388.

5. Kamiya K, Shimizu K, Igarashi A, Kobashi H, Ishii R, Sato N. Clinical evaluation of optical quality and intraocular scattering after posterior chamber phakic intraocular lens implantation. Invest Ophthalmol Vis Sci. 2012;53:3161-3166.

6. Marques EF, Ferreira TB. Comparison of visual outcomes of 2 diffractive trifocal intraocular lenses. J Cataract Refract Surg. 2015;41:354-363.

7. de Vries NE, Webers CA, Montés-Micó R, Ferrer-Blasco T, Nuijts RM. Visual outcomes after cataract surgery with implantation of a $+3.00 \mathrm{D}$ or $+4.00 \mathrm{D}$ aspheric diffractive multifocal intraocular lens: comparative study. J Cataract Refract Surg. 2010;36:1316-1322.

8. Petermeier K, Messias A, Gekeler F, Szurman P. Effect of +3.00 diopter and +4.00 diopter additions in multifocal intraocular lenses on defocus profiles, patient satisfaction, and contrast sensitivity. J Cataract Refract Surg. 2011;37:720-726.

9. Packer M, Chu YR, Waltz KL, et al. Evaluation of the aspheric Tecnis multifocal intraocular lens: one-year results from the first cohort of the food and drug administration clinical trial. Am J Ophthalmol. 2010;149:577-584.e1.

10. Cillino S, Casuccio A, DiPace F, et al. One-year outcomes with new-generation multifocal intraocular lenses. Ophthalmology. 2008;115:1508-1516.

11. Kohnen T, Nuijts R, Levy P, Haefliger E, Alfonso JF. Visual function after bilateral implantation of apodized diffractive aspheric multifocal intraocular lenses with a $+3.0 \mathrm{D}$ addition. $J$ Cataract Refract Surg. 2009;35:2062-2069.

12. Alió JL, Montalbán R, Peña-García P, Soria FA, Vega-Estrada A. Visual outcomes of a trifocal aspheric diffractive intraocular lens with microincision cataract surgery. J Refract Surg. 2013;29:756-761.

13. Vryghem JC, Heireman S. Visual performance after the implantation of a new trifocal intraocular lens. Clin Ophthalmol. 2013;7:1957-1965.

14. Lesieur G. Outcomes after implantation of a trifocal diffractive IOL [article in French]. J Fr Ophtalmol. 2012;35:338-342.

15. Sheppard AL, Shah S, Bhatt U, Bhogal G, Wolffsohn JS. Visual outcomes and subjective experience after bilateral implantation of a new diffractive trifocal intraocular lens. J Cataract Refract Surg. 2013;39:343-349.

16. Cochener B, Vryghem J, Rozot P, et al. Visual and refractive outcomes after implantation of a fully diffractive trifocal lens. Clin Ophthalmol. 2012;6:1421-1427.

17. Cochener B, Vryghem J, Rozot P. Clinical outcomes with a trifocal intraocular lens: a multicenter study. J Refract Surg. 2014;30:762-768.

18. Bozukova D, Pagnoulle C, Jérôme C. Biomechanical and optical properties of 2 new hydrophobic platforms for intraocular lenses. J Cataract Refract Surg. 2013;39:1404-1414.

19. Chassain C. Evaluation of visual performance after implantation of a double C-Loop toric intraocular lens [article in French]. J Fr Ophtalmol. 2014;37:507-513. 
20. Chassain C, Pagnouelle C, Gobin L, Rozema J. Evaluation of a new intraocular lens platform: centration and rotational stability [article in French]. J Fr Ophtalmol. 2013;36:336-342.

21. Mojzis P, Peña-García, Liehneova I, Ziak P, Alió JL. Outcomes of a new diffractive trifocal intraocular lens. J Cataract Refract Surg. 2014;40:60-69.

22. Rohart C, Lemarinel B. Thanh HX, Gatinel D. Ocular aberrations after cataract surgery with hydrophobic and hydrophilic acrylic intraocular lenses: comparative study. J Cataract Refract Surg. 2006;32:1201-1205.

23. Taketani F, Matsuura T, Yukawa E, Hara Y. High-order aberrations with Hydroview H60M and AcrySof MA30BA intraocular lenses: comparative study. J Cataract Refract Surg. 2004;30:844848.
24. Kohnen T, Allen D, Boureau C, et al. European multicenter study of the AcrySof ReSTOR apodized diffractive intraocular lens. Ophthalmology. 2006;113:584.e1.

25. Radford SW, Carlsson AM, Barrett GD. Comparison of pseudophakic dysphotopsia with Akreos Adapt and SN60-AT intraocular lenses. J Cataract Refract Surg. 2007;33:88-93.

26. Bournas P, Drazinos S, Kanellas D, Arvanitis M, Vaikoussis E. Dysphotopsia after cataract surgery: comparison of four different intraocular lenses. Ophthalmologica. 2007;221:378-383.

27. Tassignon MJ, Gobin L, Mathysen D, Van Looveren J, De Groot V. Clinical outcomes of cataract surgery after bag-in-the-lens intraocular lens implantation following ISO standard 119797:2006. J Cataract Refract Surg. 2011;37:2120-2129. 


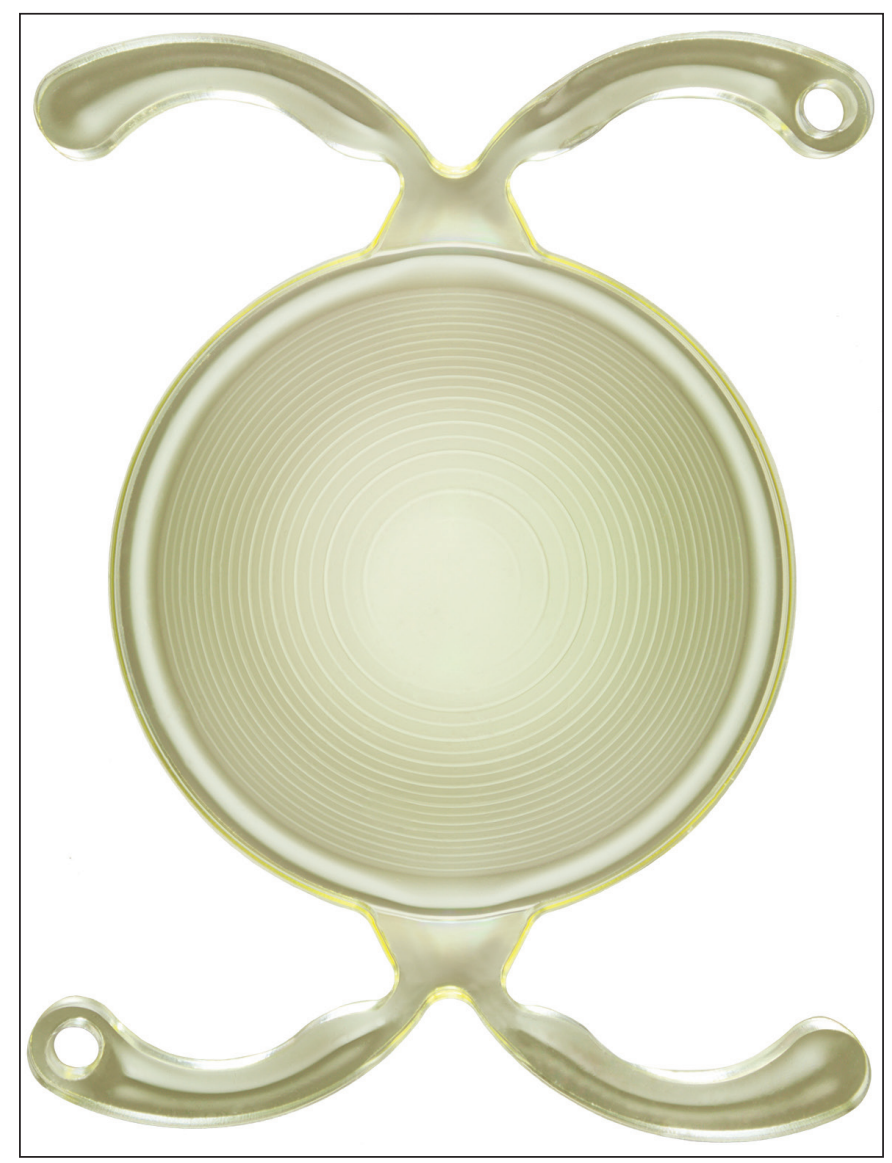

Figure A. Photograph of the "POD" IOL design (POD FineVision) with 6-mm optical diameter and 11.4-mm total diameter. The lenses are manufactured by PhysIOL, Liège, Belgium.

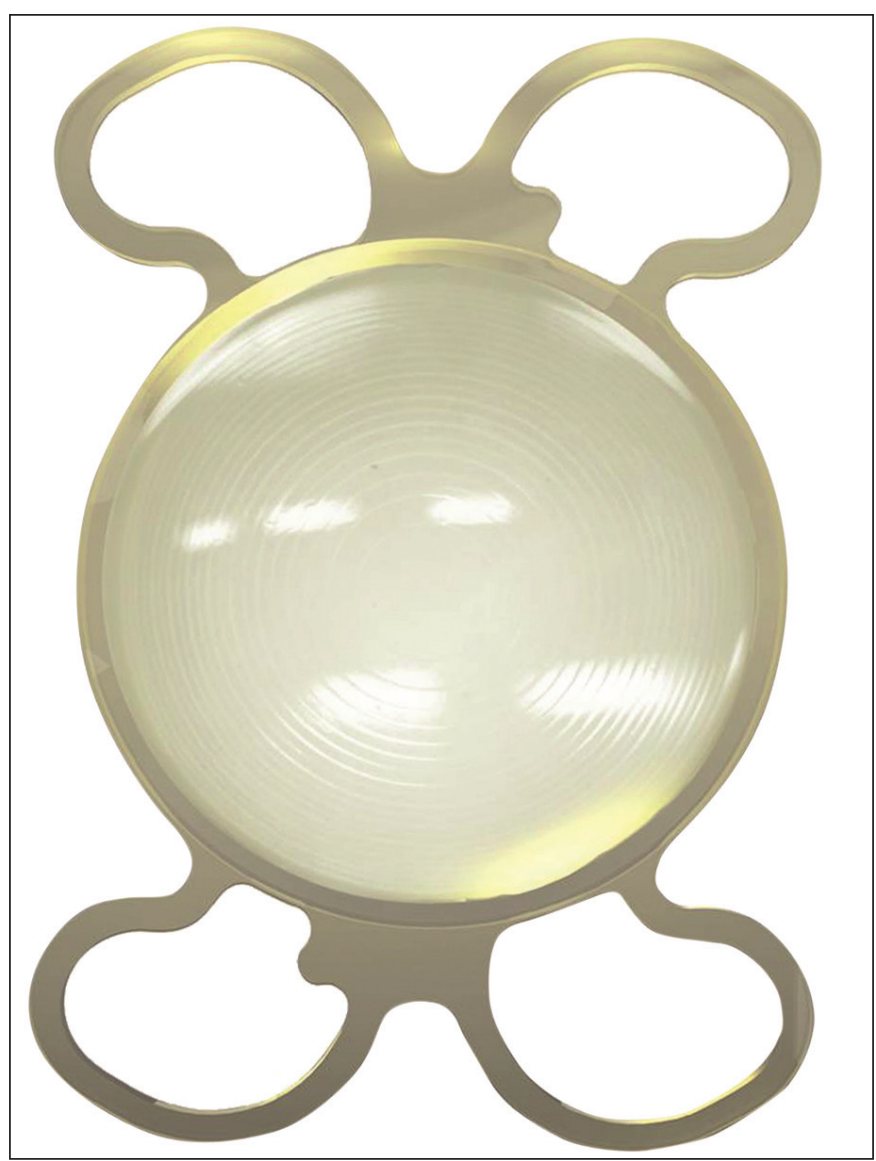

Figure B. Photograph of the MicroF design (FineVision/MicroF; PhysIOL, Belgium) with 6.15-mm optical diameter and $10.75-\mathrm{mm}$ total diameter. The lenses are manufactured by PhysIOL, Liège, Belgium.

\begin{tabular}{|c|c|c|}
\hline \multicolumn{3}{|c|}{$\begin{array}{c}\text { TABLE A } \\
\text { Descriptive Statistics of the Preoperative Parameters for Both Groups }\end{array}$} \\
\hline Parameter & POD FineVision & FineVision/MICROF \\
\hline Axial length (mm) & $23.36 \pm 0.94(21.32$ to 25.31$)$ & $23.34 \pm 0.97$ (21.19 to 25.57$)$ \\
\hline Corneal power (D) & $43.61 \pm 1.09$ (42.19 to 46.22$)$ & $43.73 \pm 1.15$ (41.80 to 46.44$)$ \\
\hline Astigmatism (D) & $-0.63 \pm 0.36(-1.54$ to -0.17$)$ & $-0.58 \pm 0.38(-1.48$ to 0$)$ \\
\hline IOL power (D) & $21.86 \pm 2.86$ (16.5 to 26.5$)$ & $21.60 \pm 2.95(15.5$ to 1$)$ \\
\hline Photopic pupil diameter (mm) & $4.14 \pm 1.0 .4(2.00$ to 6.00$)$ & $4.09 \pm 1.08(2.00$ to 6.00$)$ \\
\hline Mesopic pupil diameter (mm) & $5.24 \pm 0.87(3.80$ to 6.60$)$ & $5.20 \pm 0.92(3.48$ to 6.60$)$ \\
\hline
\end{tabular}

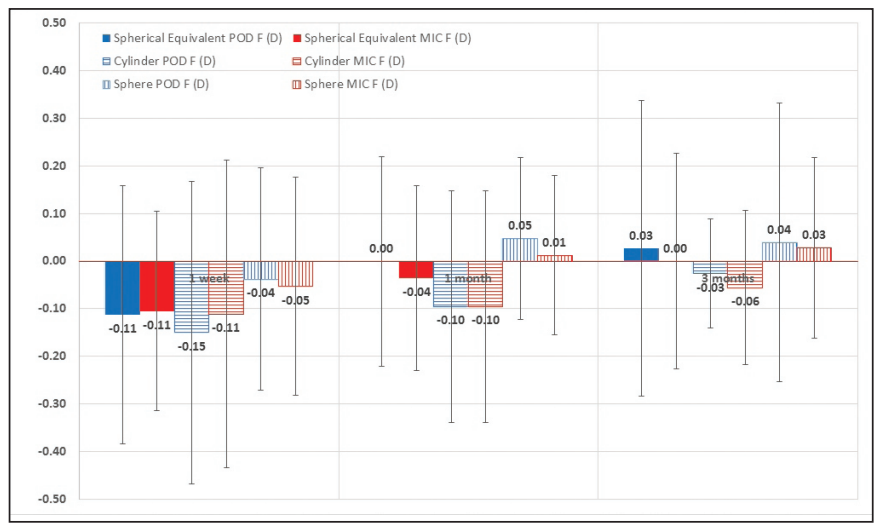

Figure C. Spherical equivalent, cylinder, and sphere at 1 week, 1 month, and 3 months (red = POD FineVision group; blue = FineVision/MicroF group). The lenses are manufactured by PhysIOL, Liège, Belgium. 